\title{
Baseline Study to Estimate the Amount of Disaster Waste Using RapidEye Data
}

\author{
Hikaru Shirai $^{a}$, Yoichi Kageyama ${ }^{\mathrm{a},{ }^{*}, \text { Azuma Ohuchi }}{ }^{\mathrm{b}}$, Makoto Nishida ${ }^{\mathrm{a}}$ \\ ${ }^{a}$ Akita University, 1-1, Tegata Gakuen-Machi, Akita 010-8502, Japan \\ ' Tohoku University, 6-6, Aramaki Aza Aoba Aoba-ku, Sendai, Miyagi 980-8579, Japan \\ *Corresponding Author: kageyama@ie.akita-u.ac.jp
}

\begin{abstract}
In the Great East Japan Earthquake that occurred on March 11, 2011, the Pacific Ocean coast of the Tohoku region suffered serious tsunami damage. To draw up reconstruction plans following great earthquakes in such areas it is necessary to estimate the amount of disaster waste. Disaster waste estimation using remote sensing data is a fundamental priority that affects all subsequent processing. Although high ground resolution remote sensing data contain detailed information, they represent a narrow scanning width and are expensive. On the other hand, remote sensing data of lower ground resolution ( 5 to $30 \mathrm{~m}$ ) are able to cover wide areas at a low cost. However, the digital number (DN) of each lower resolution pixel represents the average land cover conditions, i.e., the information provided by a pixel should be represented as a one-pixel mixed class ("mixel") instead of one-pixel one-class. In a previous study, we developed a method for unmixing mixels using the DNs from RapidEye data. We also developed a method of disaster building domain estimation using RapidEye data acquired before and after an earthquake. In this study, we propose a method to estimate the number of disaster buildings using the results of the disaster building domain, whose effectiveness was confirmed by our findings.
\end{abstract}

Keywords: remote sensing, RapidEye, mixel, disaster waste, Great East Japan Earthquake.

\section{Introduction}

In the Great East Japan Earthquake that occurred on March 11, 2011, the Pacific Ocean coast of Tohoku region suffered serious tsunami damage. In such areas, it is necessary to estimate the amount of disaster waste to draw up reconstruction plans following great earthquakes. Disaster waste estimation using remote sensing data is a fundamental priority that affects all subsequent processing ${ }^{(1)}$. Although remote sensing data of a high ground resolution contain detailed information, they represent only a narrow scanning width and are expensive. On the other hand, remote sensing data of lower ground resolution ( 5 to $30 \mathrm{~m}$ ) are able to cover wide areas at a low cost. However, the DN of each pixel represents the average land cover conditions. That is, the information provided by a pixel should be represented as a one-pixel mixed class instead of a one-pixel single class. The mixed class pixel is referred to as a "mixel"(2). Both mixels and pure pixels should be considered to accurately classify land cover conditions. It is necessary to develop a method to extract detailed information from remote sensing mixels. A method of estimating the class mixture proportion constituting the mixels has been proposed ${ }^{(2-6)}$. Moreover, Kageyama and Nishida ${ }^{(7)}$ proposed a method of unmixing a mixel to improve the ground resolution of data. However, only three classes (rice field, soil, and vegetation) were classified by the method, and complicated land cover conditions, such as disaster areas, were never classified.

In our previous studies, we proposed a method of land cover classification using Thailand Earth Observation System (THEOS) multi-spectral data of the affected area ${ }^{(8)}$. The total matching rate of the land cover classification compared to the manually classified map (using a geological map and an aerial photograph) was $90.4 \%$, with a good agreement between the two. However, to detect collapsed buildings, a ground resolution of at least $2 \mathrm{~m}$ is required. Therefore, we proposed a method of land cover classification using RapidEye, which has a higher ground resolution than THEOS $^{(9)}$. The ground resolution of RapidEye was improved to approximately $2 \mathrm{~m}$ from $6.5 \mathrm{~m}$ by the proposed method, 
and the test results suggest that it is effective in the classification of land cover conditions. The total matching rate of the land cover classification compared to the manually classified map (using geological map and aerial photograph) was $89.9 \%$, and it was $8.2 \%$ higher than for the maximum likelihood. Additionally, we proposed a method of disaster building domain estimation using RapidEye data acquired before and after an earthquake ${ }^{(10)}$. The matching rate of the results of the disaster building domain compared to the building damage map was $93.8 \%$, with a good agreement between the two. However, estimation of the amount of disaster waste has not yet been performed. In general, to estimate the amount of disaster waste, the number of disaster buildings and disaster waste generated per unit are required. In addition, the amount of disaster waste varies with the extent of building damage. Thus, to estimate the amount of the disaster waste, it is necessary to estimate the number of disaster buildings and the extent of damage to each building. In this paper, as a first step, we propose a method to estimate the number of disaster buildings using disaster building domain results.

\section{Study Area and Data Used}

\subsection{Study Area}

In the Great East Japan Earthquake of March 11, 2011, $29,742,000$ tons of waste $(18,794,000$ tons of disaster waste and 10,948,000 tons of tsunami deposit) were deposited in Iwate, Miyagi, and Fukushima Prefectures, which suffered the most serious damage ${ }^{(11)}$. The current study uses the Miyagi Prefecture coast as a study area for identifying land cover changes before and after the earthquake, and estimating the amount of disaster waste generated.

\subsection{RapidEye Data}

RapidEye data consists of five wavelength bands (visible (red, green blue), red-edge, and near-infrared). The ground resolution of RapidEye data is $6.5 \mathrm{~m}$ for Bands 1 to 5 , with a scanning width of $77 \mathrm{~km}$ and a regression period of 5.5 days $^{(12)}$. Data from April 4, 2010 (pre-earthquake data) and March 19, 2011 (post-earthquake data) with $900 \times 900$ pixel sizes were used to compare the land cover condition before and after the earthquake (Fig. 1).

\section{Proposed Method}

\subsection{Outline}

The proposed method consists of land cover classification and estimation of the number of disaster buildings.

The method of land cover classification proposed in Ref. (10), consists of five steps (blue box in Fig. 2). First, classification groups and classes are set. Second, the RapidEye data are divided into similar feature domains. Third, we calculate the supervised data using the DNs. Fourth, the class mixture proportion is estimated using the supervised data. Finally, the mixels are estimated using the class mixture proportion and unmixed pixels.

The method for estimating the number of disaster buildings consists of three steps (red box in Fig. 2). First, the disaster domain is estimated by using the results of land cover classification data obtained before and after the earthquake. Second, in the domain that could not be resolved in the previous processing, the disaster domain is estimated

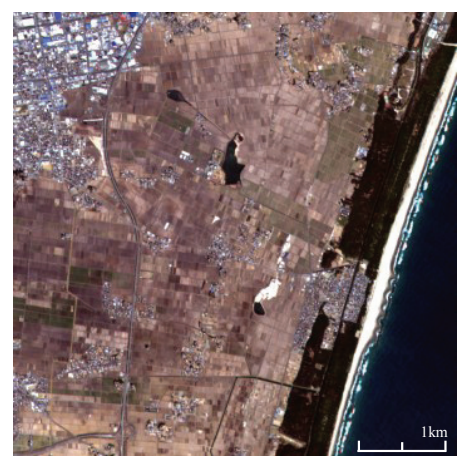

(a) Pre-earthquake data

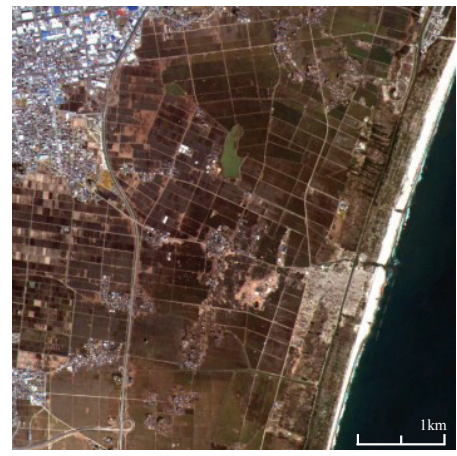

(b) Post-earthquake data

Fig. 1. RapidEye data used for analysis in the area of Wakabayashi-ku and Miyagino-ku, Sendai, Miyagi, Japan.

(RGB; Bands 3, 2, and 1).

(Including material C2010 and 2011 RapidEye S.á r.l.

All rights reserved.) 


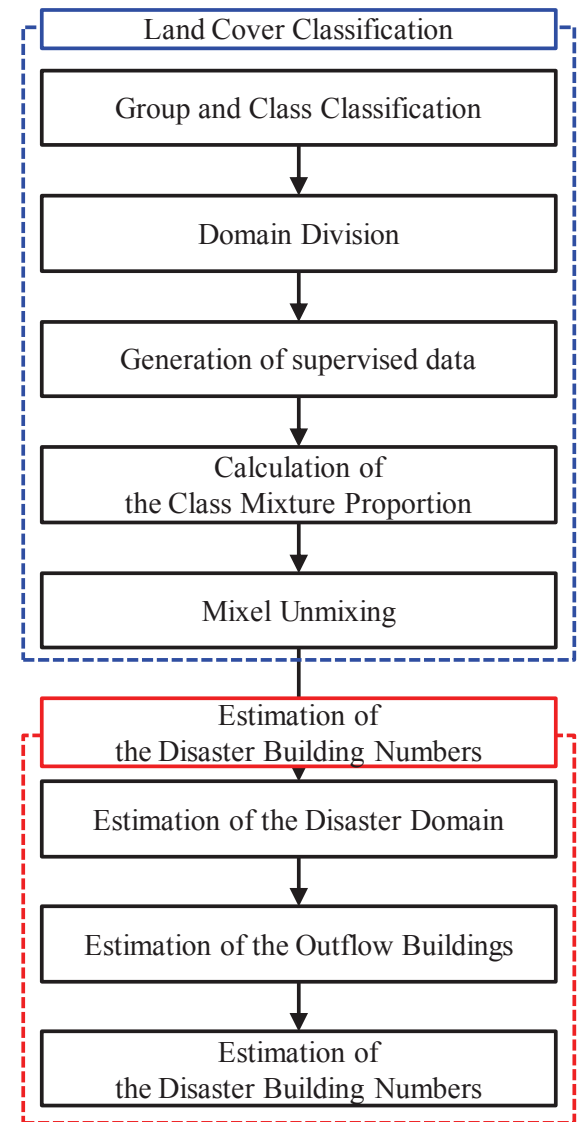

Fig. 2. Flowchart of the proposed method.

using the difference of data before and after the earthquake. Finally, the number of disaster buildings is estimated using the disaster building domain results.

\subsection{Land Cover Classification ${ }^{(10)}$}

\section{(a) Group and Class Classification}

The study area comprised a coastal area impacted by the tsunami and covered by tsunami deposits, which complicated its land cover classification. Therefore, it was necessary to detail the classes. In this paper, four classification groups (Water, Buildings, Vegetation, and Soil) and 23 additional classes (e.g., Sea, Marsh, and Ripple classes in the Water group) were set in the pre-earthquake data, and five classification groups (Water, Buildings, Flooded Soil, Vegetation, and Soil) and 22 additional classes were set in the post-earthquake data. For example, in the soil group of the pre-earthquake data, the bright brown, dark brown, and white classes were set with respect to the geology of the soil and the differences in soil moisture content.

\section{(b) Domain Division}

To enable a detailed classification, RapidEye data were clustered into five domains.
- A water-containing domain (Domain A)

- A vegetation-containing domain (Domain B)

- $\quad$ A soil domain (Domain C)

- A domain with similarly distributed features (Domain D)

- Other domains (Domain E) not classified within the above four

(c) Generation of Supervised Data

In each class set described by Section 3.2 (a), 50 points were sampled for ground truth data. Sampling points were manually set so as to be similarly distributed in the target domain. Their DN average and variance values were calculated and used as supervised data.

(d) Calculation of the Class Mixture Proportion

Based on the supervised data, the class mixture proportion was calculated using the method outlined in Ref. (2), which proved to accurately estimate mixels on an actual image $^{(6)}$.

(e) Mixel Unmixing

Mixels are not independent of adjacent pixels and can be considered to be related to their surrounding pixels. Therefore, it is possible to decompose a target pixel into pure pixels from a composition class corresponding to the class mixture proportion. When a target pixel is located in a class boundary, the DN of that pixel is expressed by a linear combination of the DN of the pure pixel whose weight coefficient is the class mixture proportion of each class in the mixel $^{(6)}$. In this study, the original pixels were divided into 3 $\times 3$ pixels using the class mixture proportion.

The mixel unmixing method consists of three steps (Fig. 3 ). First, pure pixels and mixels are classified using the class mixture proportion. When the class mixture proportion is above the threshold value $T_{P}$, the pixel is classified in the class characterized by the largest value. Subsequently, when the sum of the class mixture proportion of the top two classes is above the threshold value $T_{M}$, the pixel is classified as a mixel consisting of these classes. We checked the thresholds from 0.30 to 0.90 in increments of 0.05 , and extracted thresholds which showed results which reflected actual conditions $^{(10)}$. Second, the class mixture proportion of the top two classes is re-estimated and the pure pixels and mixels are reclassified. Finally, the mixels are unmixed based on their class mixture proportion and location information ${ }^{(7)}$.

\subsection{Estimation of Disaster Building Numbers}

(a) Estimation of the Disaster Domain

In the tsunami-impacted study area, buildings were demolished and a considerable amount of disaster waste was 


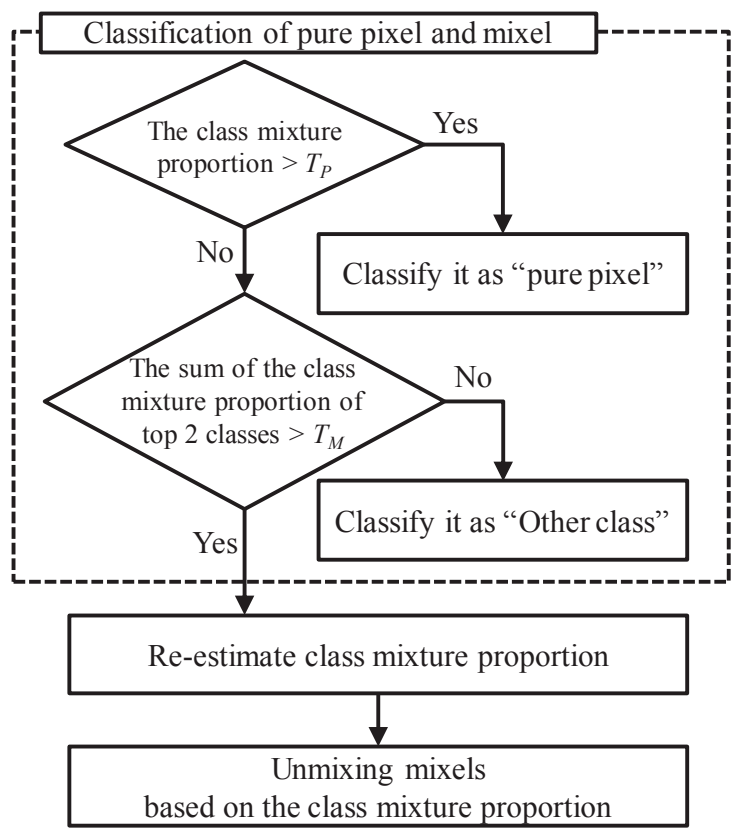

Fig. 3. Flowchart of

the mixel unmixing method ${ }^{(10)}$.

generated. It is possible to estimate the disaster waste generated based on the disaster area and waste generated per unit. In this study, similar to our previous processing to estimate the amount of disaster waste, the domain damaged by the tsunami was estimated by using the results of land cover classification obtained by the pre- and post-earthquake data. Namely, the disaster domains were estimated by using the results of land cover classification and the transition data shown in Table 1. Here,

- Case A is a domain where the building was washed out by the tsunami (outflow building)

- Case B is a domain where building debris were washed in by the tsunami (inflow building)

- Case $\mathrm{C}$ is a domain where the foundations of a building remain or a building was not impacted by the tsunami (outflow or remaining building)

- Case D is another domain not classified in the above three.

(b) Estimation of the Outflow Building Domain

In the domain classified as Case C in Section 3.3 (a), the outflow building domain was estimated from the difference in the pre- and post-earthquake data. As an example of the domain estimation using the difference value, estimation of the forest fire domain was mentioned ${ }^{(13)}$. In this case, the forest fire domain was estimated from the difference in Normalized Difference Vegetation Index (NDVI) before and after the forest fire.
Table 1. Estimation of the disaster domain by using the results of land cover classification.

\begin{tabular}{|c|c|c|c|}
\hline & \multicolumn{2}{|c|}{ Result of land cover classification } & \multirow{2}{*}{$\begin{array}{l}\text { Result of } \\
\text { estimation }\end{array}$} \\
\hline & $\begin{array}{l}\text { Result of pre- } \\
\text { earthquake data }\end{array}$ & $\begin{array}{l}\text { Result of post- } \\
\text { earthquake data }\end{array}$ & \\
\hline Case A & Building & $\begin{array}{c}\text { Water } \\
\text { Flooded Soil } \\
\text { Vegetation } \\
\text { Soil }\end{array}$ & $\begin{array}{l}\text { Outflow } \\
\text { building }\end{array}$ \\
\hline Case B & $\begin{array}{c}\text { Water } \\
\text { Vegetation } \\
\text { Soil }\end{array}$ & Building & Inflow building \\
\hline Case C & Building & Building & $\begin{array}{c}\text { Outflow } \\
\text { building } \\
\text { or } \\
\text { Remaining } \\
\text { building }\end{array}$ \\
\hline Case D & $\begin{array}{c}\text { Water } \\
\text { Vegetation } \\
\text { Soil }\end{array}$ & $\begin{array}{c}\text { Water } \\
\text { Flooded Soil } \\
\text { Vegetation } \\
\text { Soil }\end{array}$ & Other domain \\
\hline
\end{tabular}

In this study, it was necessary to select feature data for domain estimation. The feature data were selected in three steps. First, the band ratio difference value (25 kinds) was calculated using the band information obtained from the preand post-earthquake data. Second, as a reference point, we set up each of the top three kinds of colors domain with many pixels from the outflow building domain and the remaining building domain. Finally, 50 points were sampled in each region, and the average values were calculated. The sampling points were manually set so as to be similarly distributed in the target domain.

As a result, when the band ratio of Band 3 / Band 1 was used, we obtained a good estimation. Because the reflective characteristics of concrete $^{(14)}$ differ from that of building roofs ${ }^{(15)}$ in Bands 1 and 3, we considered that the difference in the band ratio indicated the outflow building and remaining building domains. In this study, we checked the thresholds from -0.60 to -0.05 in increments of 0.05 , and extracted threshold of -0.35 which showed a good result.

(c) Estimation of Disaster Building Numbers

In general, the number of disaster buildings and the disaster waste generated per unit are required to estimate the amount of disaster waste ${ }^{(16)}$. In this paper, the number of disaster buildings was estimated using equation (1). 


$$
\text { Disaster Building }=\frac{D B A \times A P}{S A \times B C}
$$

Here,

- $\quad D B A$ (Disaster Building Area pixels),

- $\quad A P$ (Area per Pixel): $4.7 \mathrm{~m}^{2}$,

- $\quad S A$ (Site Area (average in Sendai)) ${ }^{(17)}: 274.3 \mathrm{~m}^{2}$,

- $\quad B C$ (Building Coverage) ${ }^{(18)}: 40 \%, 50 \%, 60 \%$, and $70 \%$.

(d) Evaluation of Estimation Accuracy

To quantitatively evaluate the results from the proposed method, they were compared with real data on the number of disaster buildings, which was estimated using figures on the number of households in Sendai city ${ }^{(18)}$ and the disaster building map ${ }^{(19)}$. In addition, the number of vacant houses was estimated based on the rate of vacant house in Wakabayashi-ku (red area in Fig. 4) and Miyagino-ku (blue area in Fig. 4) ${ }^{(18)}$. The results are listed in Table 2.

\section{Result and Discussion}

\subsection{Results of Land Cover Classification}

Fig. 5 shows the land cover classifications by the proposed method. All pixels are expressed as pure pixels and show clear land cover boundaries. Moreover, the image dimensions change from $900 \times 900$ pixels to $2,700 \times 2,700$ pixels; i.e., the ground resolution of the RapidEye data is

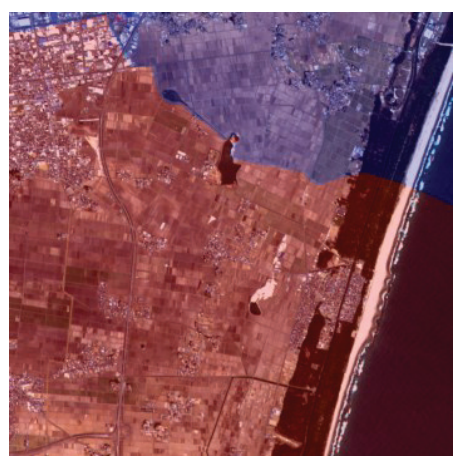

: Wakabayashi-ku $\square$ :Miyagino-ku

Fig. 4. Domain of ward.

Table 2. Number of households ${ }^{(18)}$

\begin{tabular}{|c||r|r|}
\multicolumn{3}{|c}{ and vacant houses } \\
& \multicolumn{1}{|c|}{${ }^{(18)}$. } \\
\hline \hline Wakabayashi-ku & 3,750 & \multicolumn{1}{c|}{ Vacant house } \\
\hline Miyagino-ku & 1,840 & 334 \\
\hline \hline Sub-Total & 5,590 & 1,179 \\
\hline \hline Total & & 6,769 \\
\hline
\end{tabular}

improved from $6.5 \mathrm{~m}$ to approximately about $2 \mathrm{~m}$ by mixel unmixing. However, part of the Flooded Soil group is classified as the Water group in the post-earthquake data (red circle in Fig. 5(b)), suggesting that the results reflect the actual accumulation of tsunami water in that area. Therefore, when the Water group pixels from the proposed method are in the land area of the map ${ }^{(20)}$, the pixels are considered flooded soil pixels and we estimate the disaster building domain. Fig. 6 shows the reclassification result, which was used for estimation of the disaster building domain.

\subsection{Results of Disaster Domain Estimation}

Fig. 7 shows the disaster domain estimation results. By referring to the tsunami-inundated area map ${ }^{(21)}$, it is clear that many disaster domains are estimated in the tsunamiinundated area. However, many domains of Case A (the outflow building domain was classified except the building domain in post-earthquake data) are estimated in the beach area. Since the DNs of the beach area are similar to the DNs of the building area, the beach area is classified as a building domain. Therefore, it is necessary to discriminate between

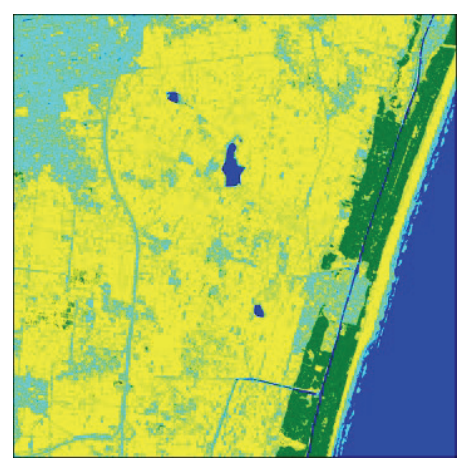

(a) Pre-earthquake data

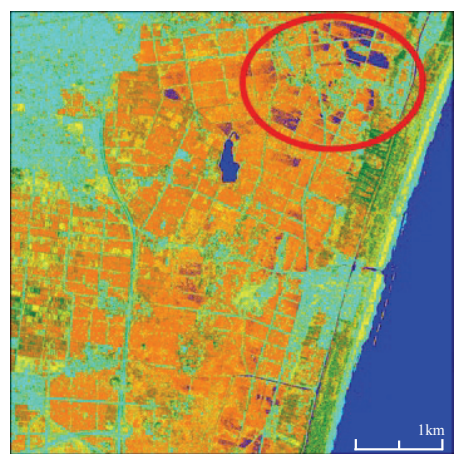

(b) Post-earthquake data

\section{:Water $\square$ :Buildings $\square$ :Flooded Soil $\square$ :Vegetation $\square$ :So}

Fig. 5. Land cover classification using the proposed method. 


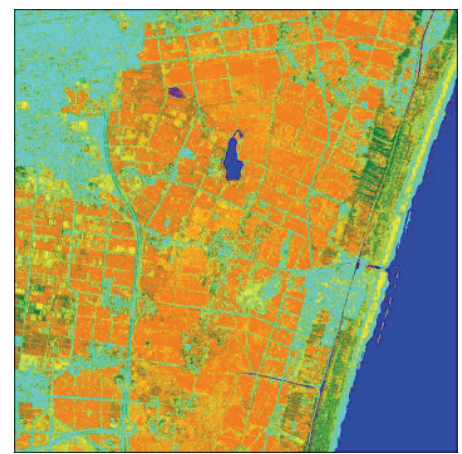

:Water $\square$ :Buildings $\square$ :Flooded Soil $\square$ :Vegetation $\square$ :Soil

Fig. 6. Land cover reclassification using the post-earthquake data.

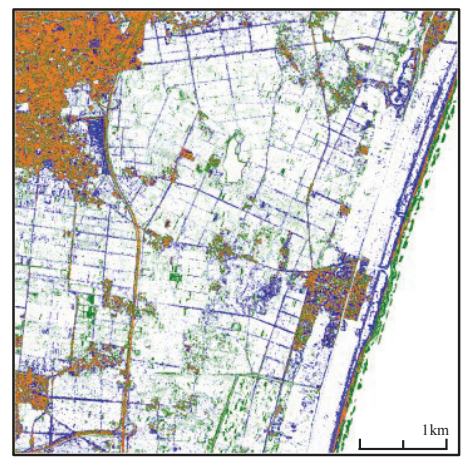

\section{:Case A $\square$ :Case B $\square$ : Case C $\square$ :Case D}

Fig. 7. Result of

disaster domain estimation.

the building area and beach area, which we will address in future work. In this study, we excluded the beach area from the disaster domain manually, by reference to the map ${ }^{(20)}$. Fig. 8 shows the reclassification.

Fig. 9 shows locations of outflow and remaining buildings in areas classified as building domain preearthquake. In the Arahama area (green circle in Fig. 9), we were able to define the outflow building domain, which was difficult to estimate using only the results of land cover classification. On the other hand, in other parts of the tsunami-flooded area, the remaining building domain is identified (e.g., the Sanbontsuka area; orange circle in Fig. 9). Using the map of actual building damage ${ }^{(22)}$, only a few outflow buildings from the tsunami are identified in the Sanbontsuka area; i.e., almost all buildings remained after the tsunami flood. Therefore, the test results are regarded as reflecting the actual condition. In areas such as Sanbontsuka with many remaining buildings the amount of disaster waste

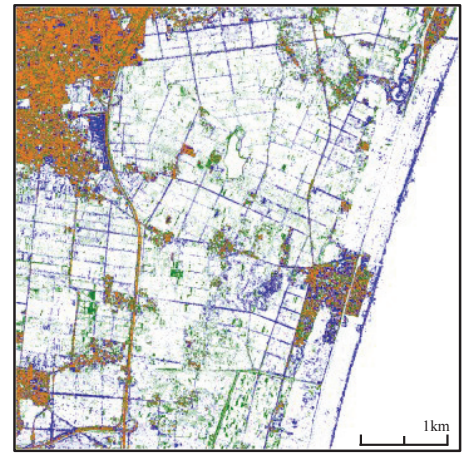

:Case A $\square$ :Case B $\square$ :Case C $\square$ :Case D

Fig. 8. Result of disaster domain re-estimation.

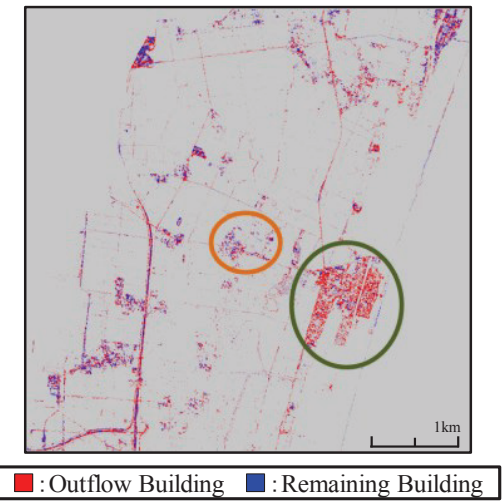

Fig. 9. Result of outflow building estimation.

varied depending on the flood extent ${ }^{(23)}$. Therefore, when estimating the amount of disaster waste, it is necessary to consider the tsunami-flooded area; namely, it is necessary to define the tsunami-flooded area by mapping the adjacent areas of remaining buildings. In future work, we will develop a method to estimate the amount of disaster waste using RapidEye data and the tsunami-flooded area.

\subsection{Results of Disaster Building Estimation}

Table 3 lists the results of the outflow building and the remaining building pixel calculations (Section 4.2). Here, since commercial buildings were not included in the number of households, the industrial area was manually removed from the disaster domain test results by referring to the map $^{(20)}$. Table 3 also estimates the number of the disaster buildings, using building coverage of $40 \%, 50 \%, 60 \%$, and $70 \%$ set up in Sendai city. As a result, it is clear that the estimated number of disaster buildings changes depending on the building coverage; therefore, it is necessary to know building coverage accurately to estimate the amount of disaster waste. Table 4 compares disaster building numbers 
Table 3. Estimation of disaster building numbers.

\begin{tabular}{|c|c|c|c|c|c|}
\hline & \multirow{3}{*}{$\begin{array}{c}\text { Estimated } \\
\text { number of } \\
\text { disaster building } \\
\text { pixels }\end{array}$} & \multirow{2}{*}{\multicolumn{4}{|c|}{$\begin{array}{l}\text { Estimated number of disaster } \\
\text { buildings } \\
\text { House coverage }(\%)\end{array}$}} \\
\hline & & & & & \\
\hline & & 40 & 50 & 60 & 70 \\
\hline $\begin{array}{l}\text { Outflow } \\
\text { building }\end{array}$ & 3,750 & 6,302 & 5,042 & 4,201 & 3,601 \\
\hline $\begin{array}{c}\text { Remaining } \\
\text { building }\end{array}$ & 1,840 & 2,182 & 1,745 & 1,455 & 1,246 \\
\hline Total & 5,590 & 8,484 & 6,787 & 5,656 & 4,848 \\
\hline
\end{tabular}

Table 4. Comparison of disaster building numbers.

\begin{tabular}{|c|c|c|c|}
\hline $\begin{array}{c}\text { House } \\
\text { coverage }(\%)\end{array}$ & $\begin{array}{c}\text { Estimation } \\
\text { result }^{* 1}\end{array}$ & Sum $^{* 2}$ & $\begin{array}{l}\text { Difference } \\
((* 1)-(* 2))\end{array}$ \\
\hline 40 & 8,484 & \multirow{4}{*}{6,769} & 1,715 \\
\hline 50 & 6,787 & & 18 \\
\hline 60 & 5,656 & & $-1,113$ \\
\hline 70 & 4,848 & & $-1,921$ \\
\hline
\end{tabular}

*1: Estimation of disaster building numbers from Table 3

*2: Sum of the households ${ }^{(18)}$ and vacant houses ${ }^{(18)}$

estimated in this study with those obtained from adding households and vacant houses. The best match between the methods is for a building coverage of $50 \%$. However, since commercial properties and storage or work sheds are not included in the sum, the original number of buildings would have been higher. Hence, we consider that a building coverage of $40 \%$ is a better reflection of actual conditions. However, we were unable to acquire detailed data of building coverage in study area. In the future, we will reappraise the test result using more detailed building coverage.

\section{Conclusion}

This paper proposed a method to estimate the number of the disaster buildings using the test results of the disaster building domain. A building coverage value of $40 \%$ provided the best fit with actual conditions.

In the future, we will develop a method to discriminate between buildings and beach areas. Also, to estimate the amount of disaster waste more accurately, we will develop a method to estimate the amount of disaster waste in consideration of the extent of damage of building.

\section{Acknowledgments}

This study was supported by SENDAI KANKYO
KAIHATSU Co., LTD. The authors thank Dr. C. Ishizawa and Dr. T. Takahashi, Akita University, Japan, and Dr. T. Takaya for their help in conducting the experiments. In addition, advice and comments given by Sendai city, Miyagi prefecture has been a great help in this study.

\section{References}

(1) T. Takaya, S. Sato, and A. Ohuchi : "Consideration about the amount presumption system of disaster wastes learned from the East Japan Great Earthquake", The 74th, National Convention of IPSJ, 3B-4, 2012 (in japanese)

(2) M. Nishida, K. Otsuka, and R. Tabata : "Estimation of Class Mixture Proportion of Mixel due to Fuzzy Reasoning”, Trans. IEE Japan, Vol.116-C, No.3, pp.359366, 1996 (in japanese)

(3) M. Matsumoto, K. Fujiku, K. Tsuchiya, and K. Arai : "Category Decomposition based on Maximum Likelihood Estimation", Journal of the Japan Society of Photogrammetry and Remote Sensing, Vol.30, No.2, pp.25-34, 1991 (in japanese)

(4) K. Yoshino: "Estimation of Landcover Ratios in Mixel IFOVs", Journal of the Japan Society of Photogrammetry and Remote Sensing, Vol.33, No.2, pp.28-33, 1994 (in japanese)

(5) A. Kitamoto and M. Takagi : "Estimating the Area Proportions of Mixels Using Mixture Density Estimation with Mixel Densities", Journal of the Institute of Electronics, Information and Communication Engineers, Vol.J81-D-2, No.6, pp.1160-1172, 1998 (in japanese)

(6) Y. Kageyama, M. Nishida, and K. Toyohuku : "Estimation of Class Mixture Proportion in Mixel Considering Component Class Number by Using Fuzzy Reasoning", Trans. IEE Japan, Vol.118-C, No.11, pp.1590-1595, 1998 (in japanese)

(7) Y. Kageyama and M. Nishida : "Image Resolution Algorithm for Mixed Pixel in Remote Sensing Data", Trans. IEE Japan, Vol.121-C, No.5, pp.961-966, 2001 (in japanese)

(8) Y. Kageyama, K. Hisa, A. Ohuchi, T. Takaya, and M. Nishida : "Method for unmixing mixels of THEOS data to estimate amount of disaster waste", Journal of Japan Society for Fuzzy Theory and Intelligent Informatics, Vol.27, No.2, pp.570-580, 2015 (in japanese)

(9) H. Shirai, Y. Kageyama, A. Ohuchi, T. Takaya, and M. Nishida : "Basic Study of Land Cover Classification 
Using RapidEye Data to Estimate the Amount of

Disaster Waste", ICIC-ELB (ICIC Express Letters, Part B: Applications; An International Journal of Research and Surveys), Vol.7, No.5, pp.1127-1133, 2016

(10) H. Shirai, Y. Kageyama, A. Ohuchi, and M. Nishida : "Estimation of the Disaster Building Domain Using RapidEye Data to Estimate the Amount of Disaster Waste", IEEJ Trans. Electrical and Electronic Engineering, Vol.11, No.S2 (in press)

(11) Ministry of the Environment of Japan Web Page : http://www.env.go.jp/ (Accessed 2016/02/15)

(12) Japan Space Imaging Corporation Web Page : http://www.spaceimaging.co.jp/ (Accessed 2016/02/15)

(13) A. Fernandez, P. Illera, and J. L. Casanova : “Automatic Mapping of Surfaces Affected by Forest Fires in Spain Using AVHRR NDVI Composite Image Data", Remote Sensing Environ, Vol.60, No.2, pp.153-162, 1997

(14) B. B. Maruthi Sridhar, T. L. Chapin, R. K. Vincent, M. J. Axe, and J. P. Frizado : "Identifying the effects of different construction practices on the spectral characteristics of concrete", Cement and Concrete Research, Vol.38, No.4, pp.538-542, 2008

(15) T. Fujimoto, T. Okada, and Y. Kondo : "Reduction of Solar Heat Gain by Using Reflective Paints for Building Envelops", Journal of Environmental Engineering, No.601, pp.35-41, 2006 (in japanese)

(16) N. Hirayama, T. Shimokawa, T. Fujiwara, T. Okayama, and Y. Kawata : "Establishment of Disaster Debris Management Based on Quantitative Estimation Using Natural Hazard Maps", WIT Trans. Ecology and the Environment, Vol.140, pp.167-178, 2010

(17) Statistics Bureau, Ministry of Internal Affairs and Communications Web Page : http://www.stat.go.jp/index.htm (Accessed 2016/06/07)

(18) Sendai City Web Page : http://www.city.sendai.jp/ (Accessed 2016/06/07)

(19) Reconstruction Assistance Investigation Archive Web Page : http://fukkou.csis.u-tokyo.ac.jp/ (Accessed 2016/06/07)

(20)ZENRIN electronic atlas Zi version 14, 2011

(21) Geospatial Information Authority of Japan Web Page : http://www.gsi.go.jp/ (Accessed 2016/02/15)

(22) International Research Institute of Disaster Science, Tohoku University Web Page : http://www.tsunami.civil.tohoku.ac.jp/hokusai3/E/inde x.html (Accessed 2016/02/15)

(23) Cabinet Office, Government of Japan: Page of the disaster prevention information 